\title{
Prostaglandin E2 induces immediate migraine-like attack in migraine patients without aura
}

\author{
M Antonova*, T Wienecke, J Olesen, M Ashina \\ From The European Headache and Migraine Trust International Congress \\ London, UK. 20-23 September 2012
}

\section{Background}

Prostaglandin E2 (PGE2) has been suggested to play an important role in the pathogenesis of migraine [1]. In the present experiment we investigated if an intravenous infusion of PGE2 would induce migraine-like attacks in patients with migraine.

\section{Methods}

Twelve patients with migraine without aura were randomly allocated to receive $0.4 \mathrm{ig} / \mathrm{kg} / \mathrm{min}$ PGE2 (Prostin ${ }^{\mathbb{B}} \mathrm{E} 2$, dinoprostone) or placebo over $25 \mathrm{~min}$ in a two-way, cross-over study. Headache intensity was recorded on a verbal rating scale, middle cerebral artery blood flow velocity (VMCA) was measured by Transcranial Doppler (TCD) and diameter of superficial temporal artery (STA) was obtained by c-series scan (Dermascan C).

\section{Results}

In total 9 migraine patients (75\%) experienced migrainelike attacks after PGE2 compared to none after placebo $(P=0.004)$. Seven out of $9(58 \%)$ patients reported the migraine-like attacks during the immediate phase (0-90 $\min )(\mathrm{P}=0.016)$. Only two patients experienced the delayed migraine-like attacks several hours after the PGE2 infusion stop ( $\mathrm{P}=0.500)$. The VMCA decreased during the PGE2 infusion $(P=0.005)$ but there was no significant dilatation of the STA $(\mathrm{P}=0.850)$.

\section{Conclusion}

The migraine-like attacks during, and immediately after, the PGE2 infusion contrast with those found in the previous provocation studies, where the other pharmacological compounds triggered the delayed migraine-like attacks several hours after the infusion. We suggest that PGE2

Danish Headache Center, Denmark may be one of the important final products involved in the generation of migraine attacks.

Published: 21 February 2013

Reference

1. Wienecke T, Olesen J, Oturai PS, et al: Prostaglandin E2(PGE2) induces headache in healthy subjects. Cephalalgia 2009, 29:509-519.

\section{doi:10.1186/1129-2377-14-S1-P113}

Cite this article as: Antonova et al:: Prostaglandin E2 induces immediate migraine-like attack in migraine patients without aura. The Journal of Headache and Pain 2013 14(Suppl 1):P113.
Submit your manuscript to a SpringerOpen ${ }^{\circ}$ journal and benefit from:

- Convenient online submission

- Rigorous peer review

- Immediate publication on acceptance

Open access: articles freely available online

- High visibility within the field

- Retaining the copyright to your article
SpringerOpen ${ }^{\odot}$

(c) 2013 Antonova et al; licensee Springer. This is an Open Access article distributed under the terms of the Creative Commons Attribution License (http://creativecommons.org/licenses/by/2.0), which permits unrestricted use, distribution, and reproduction in any medium, provided the original work is properly cited. 